\title{
Family Medicine Research: Implications for Wonca
}

\author{
Niels Bentzen, MD \\ Norwegian University of Science \\ and Technology
}

Conflicts of interest: none reported

\section{CORRESPONDING AUTHOR}

Niels Bentzen, MD

Professor of General Practice

Department of Community Medicine and

General Practice

Norwegian University of Science and Technology

Medisinsk Teknisk Forskningssenter

7489 Trondheim

Norway

niels.bentzen@medisin.ntnu.no

\begin{abstract}
The purpose of the article is to illustrate where in the lifelong curriculum of family medicine ought students, trainees, and family physicians learn about research in family medicine. The role of Wonca to promote this endeavor is discussed.

I describe the recruitment and training programs for family physicians and state the implication for Wonca to promote family medicine research in the undergraduate curriculum, during residency, and in the graduate study programs for experienced medical doctors. I describe the possible research fields in family medicine and the special methods that can be used to get reliable and valid answers to relevant questions in family medicine.

It is time for Wonca to develop a policy for family medicine research by developing a strategy to promote it. This can be done through a Wonca policy statement about family medicine research in the medical curriculum. Wonca can, in collaboration with national colleges, arrange workshops and master classes in research; create scholarships and fellowships for international family medicine researchers; influence journals and international bodies, such as the World Health Organization, governments, and colleges about the necessity of good family medical research; describe ethical guidelines for international primary care research; and create a number of databases for researchers to use.
\end{abstract}

Ann Fam Med 2004;2(Suppl 2):S45-S49. DOI: 10.1370/afm.190.

\section{INTRODUCTION}

$\bigcirc_{\mathrm{t}}^{\mathrm{e}}$ everal attempts have been made to define or describe the role of the general practitioner ${ }^{1-4}$ since Wonca was formed as a world organization for family doctors in 1972. A similar effort to write a policy document on family medicine research has not been done.

Research is seen by most family physicians as a specialist endeavor or a task necessary for the few family physicians who want to become academics. Research is not appreciated as a part of good primary care. This lack of understanding that research is an integral part of both intellectual and practical family medicine greatly influences the thinking of those who administer primary care-the politicians, practice managers, health economists, and primary care administrators - and the family physicians themselves. To change their attitude toward family medicine research, the notion that research is an integral to family medicine should be promoted.

The challenge for Wonca is how to describe family medicine research in terms that cause family physicians to regard it as a part of their specialty. Wonca must support and encourage family physicians to be active in family medicine research; promote high-quality research in family medicine, educate politicians, administrators, and managers so they understand the necessity of family medicine research; and encourage governments and donor organizations to fund international family medicine research. 


\section{RECRUITMENT AND TRAINING}

\section{Undergraduate Education}

The undergraduate curriculum in all medical schools should teach about why people seek health care and how it is delivered. By so doing, primary health care and family medicine become an essential and important part of the curriculum from its very start. Any physician who wants to practice medicine should know about the concepts of family practice, patient-centered medicine, and problem solving in primary care.

All students should spend some clinical training in primary care. Part of this time, they should be involved in projects that try to answer questions relevant to primary care. This experience will help them understand that research is about organizing curiosity, finding answers, and documenting them.

Research is for everybody; it starts in medical school and should continue throughout the whole professional career, whether in cardiology, oncology, or family medicine. By focusing on patients rather than diseases or organs, students will appreciate family medicine research as a field that complements research in the other specialties and in public health.

Implications for Wonca in the undergraduate curriculum are (1) to promote the implementation of family medicine in the undergraduate curriculum, and (2) describe the clinical training and project work and research in primary care.

\section{Internship and Residency}

Family medicine should be part of every internship program. Including it in internship training will ensure that all physicians spend some time in primary care. During this period the young physicians' curiosity should be stimulated so that it helps them in their career choice.

For the physicians who choose family medicine as their career, formal and structured specialist vocational training should be available. This training should include a specified period during which the physicians can study a relevant problem in family medicine.

Wonca's role should be to (1) describe an internship program in which primary care is an integral part ${ }_{i}(2)$ develop a vocational training plan in family medicine

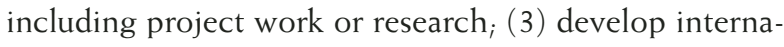
tional scholarships; and (4) influence national colleges, postgraduate universities, and others responsible for the training to incorporate family medicine research in the lifelong curriculum.

\section{Continuing Education in Family Medicine}

Some family physicians trained in research will continue their career in academic family medicine. It is important that these physicians develop further skills in family medicine research by asking important clinical and health service questions and applying or developing relevant research methods. They also need to develop educational and supervising skills so that they can inform, teach, and advise other family physicians in family medicine research.

Implications for Wonca are to (1) support postgraduate research training, (2) fund international fellowships in family medicine research, (3) develop a Web site database of research institutions and researchers in family medicine, (4) support international family medicine research conferences and master classes; and (5) accumulate funding for international family medicine research activities.

Many family physicians in clinical practice regain their curiosity after years of service work. They begin to reflect on clinical problems or interesting patients they have met in their practice. They want to find out why things happened the way they did. These physicians often need support and guidance to turn their vague questions into good research questions. It is an important task to help these family physicians find answers to their questions. By helping them use relevant research tools and strategies, they may become active researchers in their own clinical setting.

The implications for Wonca to support this development are to (1) develop models or graduate study programs for experienced family physicians, (2) create a database of relevant primary care themes and research tools, (3) develop a database of outstanding international family medicine research, and (4) make literature easily accessible through www. GlobalFamily Doctor.com.

\section{RESEARCH THEMES}

The important questions in family medicine depend on the "eyes that see," but it is more likely that a curious family physician can formulate interesting research questions and find research methods that are applicable to primary care than a physician who has no experience in family medicine.

There are many relevant clinical questions that need answers. Some patients are seen only by a family physician, who both diagnoses and manages the patient's health problem without referring to other physicians. Some patient care problems can be solved by using clinical controlled trials, but often these methods are not practical in a primary care setting, and other methods have to be used or developed.

Some problems encountered in family practice are related to patients who complain of vague symptoms from many parts of the body. The biomedical approach is insufficient to understand these patients' conditions, 
and research methods from other sciences have to be applied. A considerable portion of the research in primary care should focus on health problems that most people have most of the time. ${ }^{5}$

Epidemiological studies are important because they form the basis for our knowledge of primary care. Epidemiological research requires data about patient's disease episodes when the patient reports unspecified symptoms to when the symptoms become a defined pathological entity that can be labeled with a diagnosis. To do this research and compare results internationally, it is necessary to develop a comprehensive classification of patients' reasons for the encounter, the process of care, and the family physician's diagnostic terminology. ${ }^{6}$

Health care service research is another important topic in which family physicians should be involved. Teamwork and cooperation among the different health care workers and the different levels of health care are core issues for a health care system and for the optimal use of resources. The way we deliver health care to people has a great impact not only on their health but also on recruitment and sustainability of health care personnel, especially in rural and remote areas. We need to know more about how organizing health services affects both patients' health-seeking behavior and the use of resources.

In societies where changes in organization and financing of health care services are frequent, there is a need for monitoring and documenting the effect of such changes. Although the changes are mainly administrative, they have a great impact on the working conditions of family physicians.

Other themes are prevention of major health problems, especially those related to a population's lifestyle, such as smoking, excessive drinking and eating, and lack of physical exercise. Prevention of infectious diseases, such as measles, acquired immunodeficiency syndrome, and malaria, and early detection of treatable cancers, such as cervical uterine cancer and breast cancer, are additional large areas for primary care research.

Disease mongering has become a real threat to the balance of health care. ${ }^{7}$ Strong pharmaceutical and medical industries and special interest groups among patients, politicians, and physicians influence the demand for care by the general public. These influences can change the patient's reason for encounter and move the family physician's work away from detecting and treating specific diseases toward dealing with resourceful and demanding individuals whose main concern is fear of a disease they do not have. In a world where individualism and money play an increasing role, family physicians have to work for solidarity and fairness in the distribution of the health care resources.
The implications for Wonca are to (1) help define researchable questions, (2) help to prioritize family medicine research in developed as well as in developing countries, and (3) encourage the profession and societies to focus on the important aspects of medicine.

\section{METHODS}

To carry out research in a primary care setting, special methods and research design must be used. These methods have to be developed and described by the family physicians and other professionals working in primary care.

Wonca supports this development through the Wonca International Classification Committee (WICC) and other working parties and groups. Through the years WICC has been one of Wonca's most productive committees. Its main task has been to develop a number of comprehensive classifications for primary care. The best known is the International Classification for Primary Care, now available in its second edition (ICPC-2 $)^{6}$ and in an electronic format ICPC-2-E. ${ }^{8}$ This classification must be able to communicate with such classifications as ICD-10, which is used in secondary and tertiary health care service. ICD-10 can be mapped to other major classifications, such as SNOMED CT, ICD-10-CM, and ICD-10-AM, which ensures a conversion between these classifications and ICPC-2.

A fruitful relationship between Wonca and the World Health Organization (WHO) has resulted in establishing a working group of the center heads of the WHO Collaborating Centres on Classifications and WICC. The task is to get WHO to adopt ICPC-2 as a member of the family of classifications. ICPC-2 is one of the missing links in the WHO family of classifications. It is the only comprehensive primary care classification that enables the coding of the patient's reason for encounter and the physician's classification of the patient's health problems in diagnostic terms.

To facilitate international communication and understand the concepts relevant to family medicine, WICC has developed the Wonca Dictionary of Generall Family Practice. ${ }^{9}$ This dictionary is the first attempt to provide a comprehensive source for understanding the words, terms, and concepts we use in family medicine. It is based on "An International Glossary for General/ Family Practice, ${ }^{\prime 10}$ which mostly contains scientific terms related to family medicine.

Other tools have been adapted to the specific needs in family practice. Among these tools are the DUSOI/ WONCA severity of illness charts ${ }^{8}$ and the Dartmouth COOP/WONCA functional assessment charts. ${ }^{11}$ Both have been extensively tested internationally in family 
medicine and have been useful and valid for specific research purposes. To gain wider use, these tools must be developed further and tested in primary care settings in different parts of the world.

Other health outcome measures have been developed and modified for use in primary and ambulatory care, ${ }^{12}$ and should be available to family physicians throughout the world. Methods for recording practice activity and software programs that can retrieve data from the electronic patient records are examples of tools that can help and promote research in family practice.

It is important to look for new research methods if we want to answer research questions about patients with many or vague symptoms and with health problems that do not represent defined clinical entities, or if we want to understand why patients behave in a strange way. To gain insight into such problems, qualitative research methods are needed, and these methods are relatively new to medicine. They are not yet integrated and approved by the dominant scientific bodies in most medical schools. These methods, adopted from such sciences as anthropology, psychology, and sociology, are often based on interviews, focus groups, and other observations that can help us to understand our patients rather than simply counting them.

To promote international communication and to develop international research programs, it is important that we harmonize data about family medicine and develop terminology, definitions, and classifications that we share. Standards of good primary care research and ethical considerations must be developed to prevent exploitation of populations in developing countries for commercial reasons or scientific merit. Only an international organization such as Wonca can do this and make these standards available for family physicians throughout the world.

The implications for Wonca are to (1) develop a comprehensive database of research tools relevant in family medicine research; $(2)$ support development and tests of research tools and methods (3) support $^{2}$ adaptation of research methods and tools to suit the needs of family medicine research $h_{i}(4)$ promote international communication by harmonizing data, terminology, classifications, standards, and definitions; and (5) describe ethical guidelines for international family medicine research that supplement national guidelines.

\section{CONCLUSION}

It is now time for Wonca to determine a policy for family medicine research by developing a long-term and comprehensive strategy to promote research in family medicine and primary care.
This policy should be made known to every member organization and every family physician. It should also be made known to $\mathrm{WHO}$, governments, and other national and international bodies that want to have well-functioning comprehensive health care in which family medicine plays an important role. Through this effort, Wonca can help change the research culture among family physicians worldwide and in the medical scientific community at large.

The following are ways Wonca can promote family medicine research:

1. Write a Wonca policy statement on research in family medicine/primary care

2. Describe family medicine research in all parts of the medical curriculum

3. Arrange focused and high-quality research workshops, courses, and master classes

4. Influence journals and indexing bodies to include family medicine as a specialty heading

5. Create scholarships and fellowships for international family medicine researchers

6. Describe ethical guidelines for international primary care research and post research follow-up

7. Influence $\mathrm{WHO}$ and other international bodies, governments, and national colleges about the necessity of good family medicine research

Wonca can also create the following databases:

1. International research funding

2. Institutions with expertise in research and education

3. Mentors, supervisors, and other resource persons

4. Family medicine research tools, methods, and strategies

5. Family medicine research literature and bibliographies

6. International research networks, audits, and working groups

7. Models of successful family medicine research projects

8. Harmonized data, terminology, definitions, standards, and classifications

To read or post commentaries in response to this article, see it online at http://www.annfammed.org/cgi/content/full/2/suppl_2/S45.

Key words: Family medicine research; family doctors; primary care, research; disease classification; International Classification of Primary Care ICPC; general practice

A version of this paper was presented at the Wonca Research Conference, Kingston, Ontario, Canada, March 8-11, 2003.

Acknowledgments: Professor Manfred Maier, David Mant, Geoffrey Hodgetts, and Roger Strasser have critically reviewed the first draft, and I thank them for their help and encouragement. 


\section{References}

1. Leeuwenhorst Group. The General Practitioner in Europe: A Statement by the Working Party Appointed by the European Conference on the Teaching of General Practice. Netherlands: Leeuwenhorst, Netherlands; 1974.

2. Olesen F, Dickinson J, Hjortdahl P. General practice - time for a new definition. BMJ. 2000;320,354-357.

3. Evans P, ed. The European Definition of General Practice/Family Medicine. London: Wonca Europe; 2002.

4. Boelen C, Haq C, Hunt V, Rivo M, Shahady E. Improving Health Systems: The Contribution of Family Medicine. A Guidebook. Wonca, Singapore: Bestprint Printing Company; 2002.

5. Nutting PA, Green LA. Practice-based research networks: reuniting practice and research about the problems most people have most of the time. J Fam Pract. 1994;38:335-336.

6. WICC, Wonca International Classification Committee. International Classification of Primary Care, ICPC-2. 2nd ed. Oxford: Oxford University Press; 1998.
7. Moyniham R, Herth I, Henry D. Selling sickness: the pharmaceutical industry and disease mongering. BMJ 2002;324:886-981.

8. Okkes IM, Veldhuis M, and Lamberts H. Severity of episodes of care assessed by family physicians and patients: The DUSOI/WONCA as an extension of the International Classification of Primary Care (ICPC). Fam Pract. 2002;19:350-356.

9. Bentzen N, ed. Wonca Dictionary of General/Family Practice. Copenhagen: Maanedsskrift for Praktisk Laegegerning; 2003.

10. Bentzen N. An international glossary for general practice/family medicine. Fam Pract. 1995;12:341-369.

11. Scholten JHG, Van Weel C. Functional Status Assessment in Family Practice. World Organization of Family Doctors. Lelystad: Meditekst; 1992.

12. Hutchinson A, Bentzen N, König-Zahn C. Cross Cultural Health Outcome Assessment; A User's Guide. ERGHO, Ruinen, Netherlands: Drukkerij Bariet bv; 1996. 